\title{
DESCARGa SÓlIDA EM SUSPENSÃo EM UMA BACIA HIDROGRÁFICA COM A PREDOMINÂNCIA DE PASTAGEM
}

\author{
Nicole Lopes Bento ${ }^{1}$, Jhones da Silva Amorim² ${ }^{2}$ Flávia Mariani Barros ${ }^{3}$, Danilo Paulucio da Silva ${ }^{3}$
}

\begin{abstract}
1 Discente de mestrado no Programa de Pós-Graduação em Engenharia Agrícola na Universidade Federal de Lavras, Campus Universitário, Caixa Postal 3037, CEP 37200-000. Lavras/MG.

2 Discente de doutorado no Programa de Pós-Graduação em Recursos Hídricos em Sistemas Agrícolas na Universidade Federal de Lavras, Campus Universitário, Caixa Postal 3037, CEP 37200-000. Lavras/MG.

3 Docente na Universidade Estadual do Sudoeste da Babia Estrada Itapetinga/Itambé, s/n, CEP: 457000-00, Itapetinga - BA, Brasil.
\end{abstract}

Recebido em 04 de abril de 2019. Aceito em 03 de outubro de 2019. Publicado em 27 de dezembro de 2019.

Resumo - A perda de aproximadamente dez hectares de terras produtivas a cada ano no mundo em decorrência da erosão do solo é um relevante problema ambiental e socioeconômico. Diante disso, este estudo objetivou avaliar a descarga de sedimentos (Qs) na bacia hidrográfica do rio Catolé Grande, Bahia, relacionando-a com a descarga líquida (Q) e turbidez. Foram realizadas 34 coletas durante o ano de 2015 em uma seção de controle situada no município de Itapetinga. As análises das variáveis seguiram o que preconiza a APHA e a relação entre elas foi avaliada utilizando os coeficientes de determinação $\left(\mathrm{R}^{2}\right)$ e raiz quadrada do erro médio (RMSE). A perda máxima de solo encontrada foi de 83,59 Ton.dia ${ }^{-1}$ no mês de julho e o modelo que melhor explicou Qs em função da Q no período de estudo foi o potencial, com valores de $\mathrm{R}^{2}$ e RMSE de 0,911 e 4,824, respectivamente. Observou-se também o aumento da Qs em função do acréscimo da precipitação total nos sete dias antecedentes às coletas, o que pode estar relacionado ao uso predominantemente de pastagem na bacia. Não foi observado uma correlação significativa entre a turbidez e a Qs na faixa de vazão deste estudo.

Palavras-chave: Hidrossedimentologia; Concentração de Sedimento em Suspensão; Vazão.

\section{DESCARga SÓLIDA EN SUSPENSIÓN EN UNA CUENCA HIDROGRÁFICA CON PREDOMINIO DE PASTOREO}

RESUMEN - La pérdida de aproximadamente diez hectáreas de tierras productivas cada año en todo el mundo como resultado de la erosión del suelo es un problema ambiental y socioeconómico significativo. Por lo tanto, este estudio tuvo como objetivo evaluar la descarga de sedimentos (Qs) en la cuenca del río Catolé Grande, Bahía, relacionándola con la descarga de líquidos (Q) y la turbidez. Durante 2015 se realizaron 34 recolecciones en una sección de control ubicada en el municipio de Itapetinga. Los análisis de las variables siguieron lo que recomienda la APHA y se evaluó la relación entre ellas utilizando los coeficientes de determinación $\left(\mathrm{R}^{2}\right)$ y la raíz cuadrada del error medio (RMSE). La pérdida máxima de suelo encontrada fue 83,59 Ton.day-1 en julio y el modelo que mejor explicó Qs en función de Q en el período de estudio fue el potencial, con valores de $\mathrm{R}^{2}$ y RMSE de 0,911 y 4,824, respectivamente. También hubo un aumento en Qs debido al aumento en la precipitación total en los siete días previos a la recolección, lo que puede estar relacionado con el uso predominante de pasto en la cuenca. No se observó correlación significativa entre turbidez y Qs en el rango de flujo de este estudio.

Palabras Clave: Hidrosedimentología; Concentración de sedimento en suspensión; Flujo.

\section{DischaRgE OF SEDIMENTS AND CHANGES IN TURBIDITY IN A PREDOMINANT PASTURE BASIN}

ABstract - The loss of approximately ten hectares of productive land each year worldwide due to soil erosion is a significant environmental and socioeconomic problem. Therefore, this study aimed to evaluate the sediment discharge (Qs) in the Catolé Grande river basin, Bahia, relating it to the liquid discharge (Q) and turbidity. Thirty-four collections were carried out during 
2015 in a control section located in the municipality of Itapetinga. The analysis of the variables followed what the APHA recommends and the relationship between them was evaluated using the coefficients of determination $\left(\mathrm{R}^{2}\right)$ and square root of the mean error (RMSE). The maximum soil loss found was 83.59 Ton.day ${ }^{-1}$ in July and the model that best explained Qs as a function of $\mathrm{Q}$ in the study period was the potential, with $\mathrm{R}^{2}$ and RMSE values of 0.911 and 4.824, respectively. There was also observed an increase in Qs due to the increase in total precipitation in the seven days preceding the collections, which may be related to the predominant use of pasture in the basin. No significant correlation was observed between turbidity and Qs in the flow range of this study.

KeYwords: Hydrossedimentology; Concentration of Sediment in Suspension; Flow rate.

\section{INTRODUÇÃO}

A erosão do solo tem se tornado um dos problemas ambientais mais sérios ao redor do mundo e acarretado consequências como enchentes, redução do volume útil de reservatórios, perda de nutrientes do solo e redução na produtividade das áreas agrícolas, das quais cerca de dez hectares de terras produtivas são perdidos a cada ano (Zhaoet et al. 2013; Keesstra et al. 2016).

Em regiões tropicais como o Brasil, a erosão do solo ocorre predominante sob a ação da água. Este fenômeno é denominado erosão hídrica e ocorre pela ação das gotas de chuva e do escoamento superficial que promovem a remoção, transporte e deposição de partículas do solo, as quais, dependendo das dimensões, podem ser carreadas com maior facilidade até as áreas de menor declividade (Shi et al. 2012). Estima-se que a erosão hídrica afeta cerca de 1094 milhões de hectares no mundo (Da Rocha Junior et al. 2017) e no Brasil a perda de solo a partir deste fenômeno apresenta valores entre 600 e 800 milhões de toneladas por ano (Merten e Minella 2013).

O uso e ocupação do solo de forma inadequada, crescimento urbano, expansão das fronteiras agrícolas entre outros fatores têm intensificado os processos erosivos. A maioria dos estudos referentes à erosão do solo é realizada em terras agrícolas ou locais que houveram mudanças no uso e cobertura para o desenvolvimento de cultivos. É possível encontrar trabalhos em áreas de pastagem (Jemai et al. 2012; Shakesby et al. 2015), mas esses são poucos (Da Rocha Junior et al. 2017). Sendo assim, é necessário que sejam realizados estudos sobre o processo erosivo em regiões onde áreas de pastagem são predominantes, em especial no Brasil onde $20 \%$ das áreas são utilizadas para tal finalidade (Da Rocha Junior et al. 2014) e a pecuária é uma atividade econômica representativa no país.

O principal destino para as partículas erodidas do solo são os cursos d'águas. Tais partículas trazem consigo problemas de natureza física, química e biológica que podem comprometer a oferta hídrica da região (Sousa et al. 2012) e contaminar os cursos d'água (Shi et al. 2012). Exemplo claro da contaminação das águas por sedimentos foi a elevada concentração lançada no rio Doce em acidente ocorrido no município de Mariana em Minas Gerais - Brasil no ano de 2015 e a contaminação do Rio Paraopeba na região de Brumadinho em 2019.

Considerando que todo aporte de sedimentos de uma bacia hidrográfica pode ser observado em uma seção de controle que drene suas vertentes (Luíz et al. 2012), o monitoramento da descarga de sedimentos total neste ponto pode ser entendido como a perda de solo desta bacia. Desta forma, a descarga de sedimentos pode ser avaliada em nível de bacia e nortear as diretrizes da gestão ambiental de forma adequada auxiliando na preservação dos recursos naturais (Sari et al. 2017).

Em estudo desenvolvido pela UFAL (FAPEAL 2019) em relatório sobre a atual situação ecossistêmica do São Francisco destaca-se que agrotóxicos são carregados pela água das chuvas quando esta atinge o solo, por intermédio do escoamento superficial devido a erosão hídrica, sendo o acúmulo destas substâncias tóxicas no organismo resultando em doenças que acometem a população, que vão desde tipos de cânceres, problemas no trato digestivo, úlceras, distúrbios gástricos, à doenças psiquiátricas e psicológicas. Constatou-se ainda neste mesmo estudo, altos índices de coliformes fecais na água de todas as cidades visitadas pela expedição, detectando não somente bactérias, 
como ainda o excesso de matéria orgânica e substâncias como nitrogênio e fósforo refletindo impactos do elevado transporte e acúmulo de sedimentos nesta bacia hidrográfica.

$\mathrm{O}$ aporte de sedimentos em cursos d'água altera as variáveis de qualidade de água, uma vez que impede a penetração de luz e radiação solar, reduz as taxas de atividade fotossintética afetando o ecossistema aquático, além de introduzir poluentes que modificam a qualidade da água (Vestena 2009). Estas alterações podem ser observadas por meio de variações nos valores da turbidez deste curso d'água. Alguns trabalhos têm utilizado tecnologias para monitorar a turbidez como forma de estimar a concentração de sedimentos (Harrington e Harrington 2013; Haimann et al. 2014), contudo Sari et al. (2017) destacam que este método ainda é susceptível a erros, sendo o método tradicional de monitoramento o mais confiável.

Nesse contexto, o objetivo deste estudo foi (i) obter a descarga de sedimentos na bacia hidrográfica do rio Catolé Grande, Bahia, (ii) classificá-la quanto a perda de solo em Ton.(ha.ano) ${ }^{-1}$, (iii) determinar a relações entre descargas líquida e sólida e (iv) o comportamento da variável turbidez.

\section{MATERIAL E MÉtodos}

\section{Área de Estudo}

A bacia hidrográfica do rio Catolé Grande (BHCG) localiza-se no Sudoeste do estado da Bahia e está inserida na bacia do rio Pardo (Figura 1). O rio principal que dá nome à bacia nasce no município de Barra do Choça e a foz está situada no município de Itapetinga. A área de drenagem é de $3127,77 \mathrm{~km}^{2}$ e abrange os municípios de Vitória da Conquista, Itambé, Caatiba, Planalto e Nova Canaã. Além de percorrer aproximadamente 9,5 km de extensão em perímetro urbano de Itapetinga, ele é o principal manancial de abastecimento público das cidades da região.

Figura 1. Localização da área de estudo BHCG.
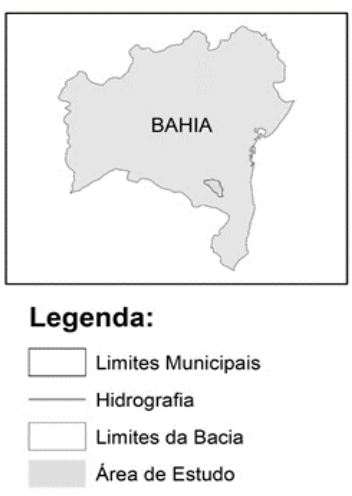
Sistema de Coordenadas:
GSC South American 1969 Datum: SAD69
Unidades: $\mathrm{Km}$
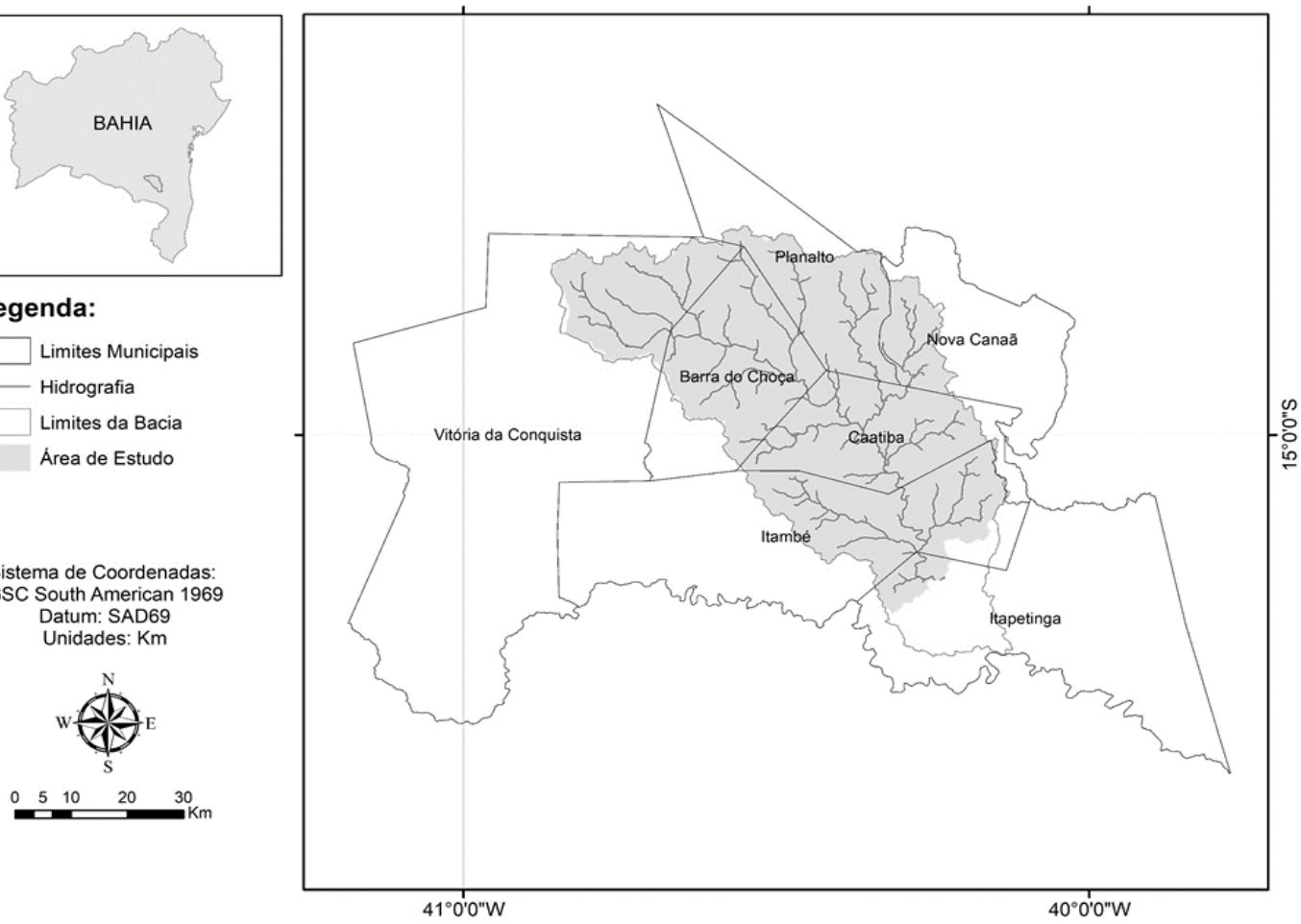
A seção de controle deste trabalho está localizada nas coordenadas $15^{\circ} 14^{\prime}$ 6,3's e $40^{\circ} 16^{\prime}$ 30,7'” e drena uma área de 2884,14 $\mathrm{Km}^{2}$ que corresponde a $91,1 \%$ da área total da BHCG. Ela foi instalada em trecho retilíneo com largura e declividade aproximadamente uniformes situando-se à montante do município de Itapetinga.

Com base em levantamentos da Comissão Executiva do Plano da Lavoura Cacaueira (CEPLAC) e Empresa Brasileira de Pesquisa Agropecuária (EMBRAPA), Amorim (2016) identificou o Latossolo Vermelho Amarelo Distrófico típico (51,52\%), Chernossolo Argilúvico Órtico típico (46,76\%), Argissolo Vermelho Amarelo Eutrófico abrúptico $(1,22 \%)$ e Nitossolo Háplico Eutrófico férrico saprolítico $(0,50 \%)$ como as classes de solo presentes na BHCG.

Segundo critérios definidos pelo SiBCS (EMBRAPA 2006), os Latossolos referem-se a solos minerais e homogêneos com pouca diferenciação entre horizontes, profundos, bem drenados, com baixa capacidade de troca de cátions, de textura média a fina e frequentemente pouco férteis. Os Chernossolos são solos de desenvolvimento pouco avançado, originários de rochas ricas em magnésio e cálcio, ricos em matéria orgânica, com alta saturação por bases e com argila em alta atividade. Os Argissolos possuem presença da mistura dos óxidos de ferro hematita e goethita, apresentam de baixa a muito baixa fertilidade natural, com reação fortemente ácida e argilas de atividade baixa. Os Nitossolos são de média profundidade, bastante intemperizados, baixa diferenciação de horizontes, textura argilosa ou muito argilosa, com argilas de atividade baixa.

As classes de solos seguidos dos seus respectivos valores de erodibilidade são apresentados na Tabela 1. Estes dados foram compilados por Silva e Alvares (2007) com base em diversos trabalhos com intuito de elaboração de um banco de dados sobre erodibilidade para as classes de solos. Tais informações são importantes para a identificação e/ou comparação entre potencialidade de perda de solo com a descarga de sedimentos na BHCG.

Tabela 1. Classes de solos e seus respectivos valores de erodibilidade

\begin{tabular}{cc}
\hline Classe de Solo & $\begin{array}{c}\text { Erodibilidade média (K) } \\
\text { (t.ha-1.MJ-1.mm-1) }\end{array}$ \\
\hline Latossolo & 0,0162 \\
\hline Chernossolo & 0,0309 \\
\hline Argissolo & 0,0425 \\
\hline Nitossolo & 0,0237 \\
\hline
\end{tabular}

Fonte: Silva e Alvares (2007)

O uso e ocupação do solo teve como base os dados do Laboratório de Processamento de Imagens e Geoprocessamento (LAPIG 2018) com referência ao levantamento do IBGE para o Mapeamento do Uso do Solo no Brasil para os anos 2000, 2010, 2012 e 2014. As classes de uso e ocupação do solo da BHCG e seus respectivos percentuais estão apresentados na Tabela 2 e a espacialização destas estão na Figura 2, sendo tais procedimentos realizados em ambiente SIG com auxílio do software ArcGis 10.6 (Esri 2012). 
Figura 2. Mapa de uso e ocupação de solo da área de estudo.
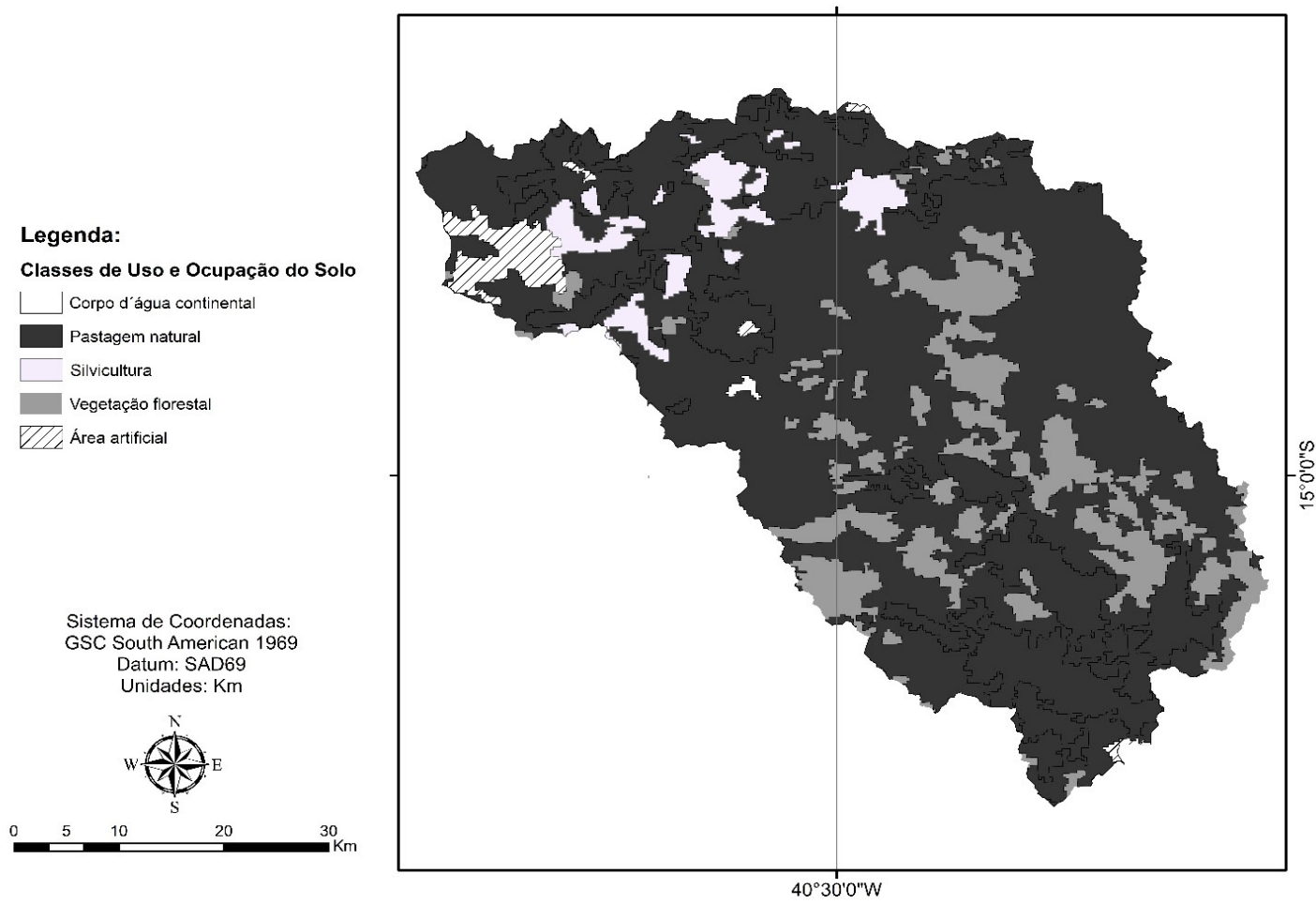

Fonte: Lapig (2018).

Observa-se que o uso e ocupação do solo da área é expressivamente destinado às pastagens extensivas, com aproximadamente $78,948 \%$ da área de estudo (Tabela 2). Nesta região de estudo a atividade agropecuária é de grande abrangência (Lima e Pinto 2011).

Tabela 2. Quantificação do uso e ocupação do solo na área de estudo

\begin{tabular}{ccc}
\hline Classe de Ocupação & $\mathbf{K m}^{\mathbf{2}}$ & $\mathbf{\%}$ \\
\hline Área artificial & 65,479 & 2,310 \\
Silvicultura & 109,733 & 3,872 \\
Vegetação florestal & 417,966 & 14,748 \\
Pastagem & 2237,45 & 78,948 \\
Corpo d'água continental & 3,437 & 0,121 \\
\hline TOTAL & 2834,065 & 100 \\
\hline
\end{tabular}

Medição da descarga líquida (Q), descarga de sedimentos (Qs) e turbidez, (T)

As 34 campanhas de medições diretas foram realizadas entre os meses de janeiro a outubro de 2015, compreendendo período seco e chuvoso na região. As variáveis hidrossedimentológicas monitoradas foram: área da seção transversal, velocidade média, descarga líquida, sedimentos suspensos e turbidez. Todos os equipamentos utilizados para medições e coletas pertencem ao Laboratório de Dispersão de Poluentes da Universidade Estadual do Sudoeste da Bahia (UESB), Campus de Itapetinga, Bahia.

A área da seção transversal foi determinada por meio de levantamento batimétrico local, metro a metro, segundo a metodologia descrita por Pruski et al. (2006). A velocidade média foi obtida pelo método convencional do molinete hidrométrico, marca Global Water e modelo FP211, em subseções com largura de dois metros ao longo 
da seção transversal do rio, conforme metodologia proposta por CETESB (2011). O posicionamento vertical do equipamento no centro de cada subseção foi realizado em diferentes profundidades conforme metodologia descrita em de Pruski et al. (2006). A descarga líquida (Q) foi obtida pelo produto da velocidade média do escoamento na calha do rio pela área da seção transversal, dado no Sistema Internacional de Unidades, em metros cúbicos por segundo $\left(\mathrm{m}^{3} \cdot \mathrm{s}^{-1}\right)$.

As amostragens para determinação da concentração de sedimentos suspensos (CSS) foram realizadas com auxílio de amostrador de sedimentos modelo USDH-48. O método de amostragem utilizado foi do tipo pontual de integração na vertical (Metodologia Clássica) (Carvalho et al. 2000). A quantificação da CSS foi realizada, em laboratório utilizando o método gravimétrico por diferenças de massa conforme metodologia descrita em Standard Methods for Examination of Water and Wastewater (APHA 2012).

A determinação da descarga de sedimentos (Qs) em suspensão segue o método modificado de Einstein (ou método de Colby 1957), citado por Carvalho (2008) (Equação 1). Ele é baseado no produto entre a descarga líquida $\mathrm{em} \mathrm{m}^{3} \cdot \mathrm{s}^{-1}$, a concentração total no canal de sedimentos $\left(\mathrm{mg} \cdot \mathrm{L}^{-1}\right)$, e o tempo (s).

$$
\text { Qs }=\text { Q } * \text { ES. } 2
$$

Onde:

Qs= descarga de sedimentos, Ton.dia ${ }^{-1}$;

$\mathrm{Q}=$ descarga líquida, vazão, $\mathrm{m}^{3} \cdot \mathrm{s}^{-1}$;

CSS = concentração de sedimentos, mg. $\mathrm{L}^{-1}$;

A turbidez foi determinada em laboratório pelo método nefelométrico com a utilização de um turbídimetro marca Digimed, modelo DM-TU - 0 a 1000 UNT.

\section{Análises Estatísticas}

A relação entre as variáveis foi verificada a partir do ajuste de regressões. Testou-se diversos modelos para obtenção da equação de ajuste, sendo o melhor ajuste determinado com base no coeficiente de determinação $\left(\mathrm{R}^{2}\right)$ e a raiz quadrada do erro médio (RMSE), com base nos dados obtidos nas coletas de campo e nas análises laboratoriais, por intermédio de planilha eletrônica.

\section{RESUltados E Discussão}

Na Figura 3 estão apresentados os resultados da CSS para a BHCG. No período estudado, essa concentração variou de 74,24 mg.L $\mathrm{L}^{-1}$ a 139,45 mg.L $\mathrm{L}^{-1}$, nas coletas de 30/abril e 12/janeiro, respectivamente. Verifica-se maiores valores de CSS no período compreendido entre janeiro e março que também corresponde aos meses mais chuvosos na região conforme as normais climatológicas (1981-2010) divulgadas pelo INMET (INMET 2019). Os períodos de abril e maio foram os que apresentaram as menores concentrações coincidindo com os meses secos. 
Figura 3. Comportamento da concentração (CSS) de sedimentos em uma seção no rio Catolé Grande.

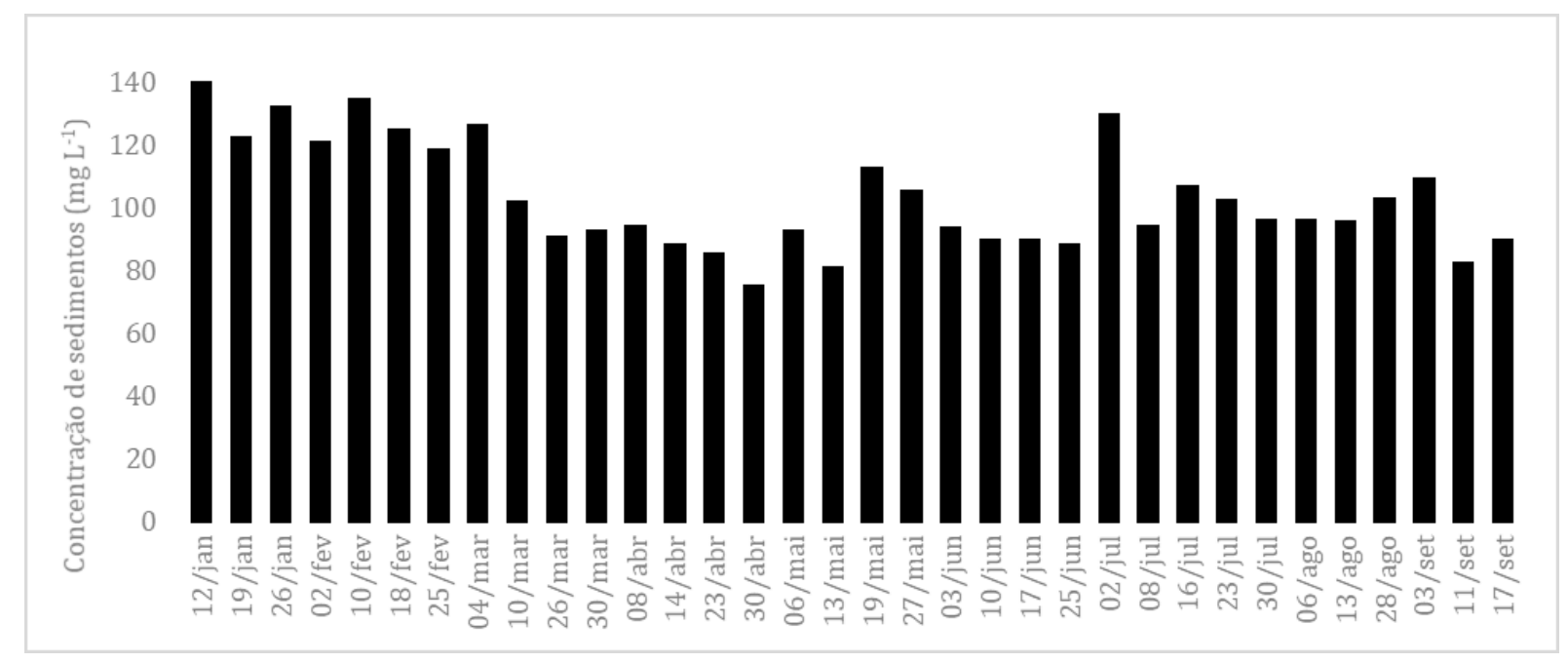

Os resultados evidenciam a influência do período chuvoso sobre a CSS na BHCG o que também foi verificado em estudos de Basso et al. (2011) realizado no arroio Dilúvio, Porto Alegre; Nogueira et al. (2012) nos principais afluentes do reservatório da UHE Barra dos Coqueiros, Goiás; Silva Jr et al. (2011) na Bacia do Mimoso, inserida na bacia representativa do Alto Ipanema no semiárido pernambucano.

$\mathrm{Na}$ Figura 4 estão apresentados os resultados da descarga sólida (descarga de sedimentos) e descarga líquida (vazão). Percebe-se que a descarga de sedimentos acompanha o comportamento da descarga líquida. Tal característica é observada nos eventos de maior valor de descarga de líquida (02/jul de 7,52 m.s ${ }^{-1}$ ) e menor (23/ abr de $\left.1,99 \mathrm{~m}^{3} \cdot \mathrm{s}^{-1}\right)$ sendo que as descargas de sedimentos nestes eventos foram de 83,59 Ton.dia ${ }^{-1}$ e 14,61 Ton.dia ${ }^{-1}$, respectivamente.

Figura 4. Curva comportamento Descarga Sólida (sedimentos) e Descarga Líquida (vazão).

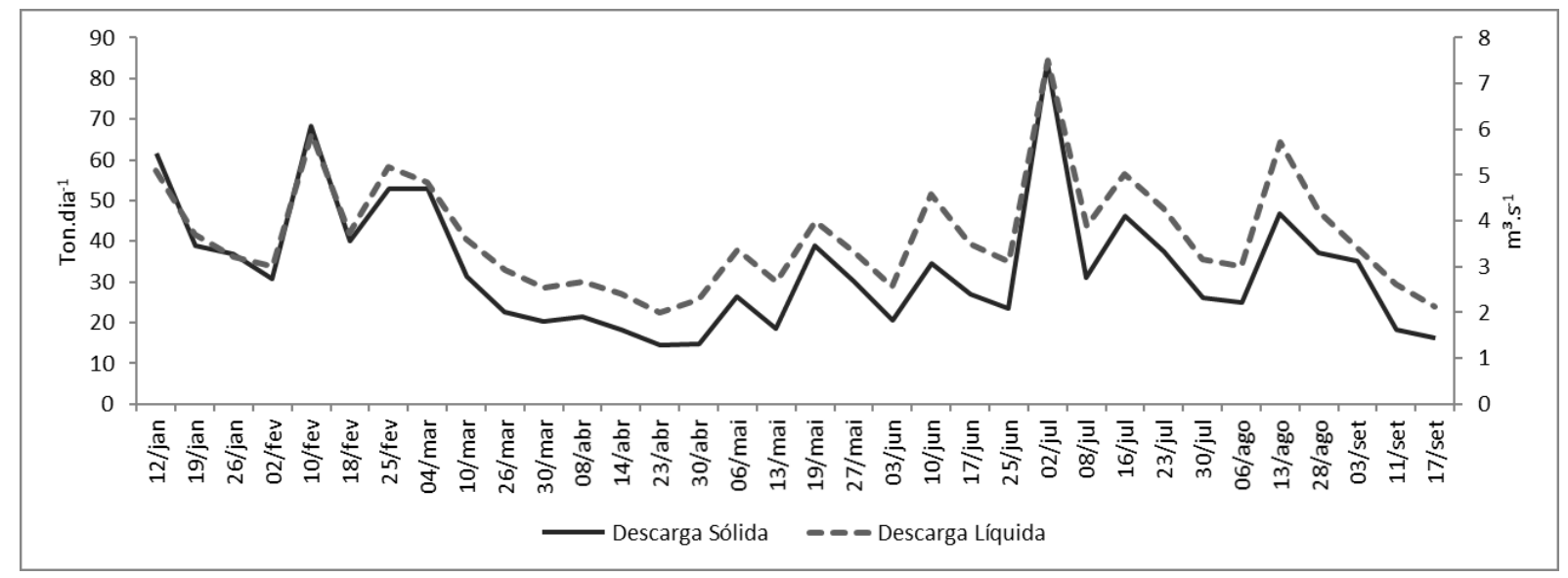

Morais (2015) identificou que o pico de vazão coincide com o pico da descarga de sedimentos, assim como foi observado na BHCG (Figura 4). Da mesma forma, menores valores de vazão acarretaram em menor descarga de sedimentos. Tais aspectos podem estar relacionados à diferença entre os índices pluviométricos ao longo das estações do ano. Desta forma, períodos com maiores lâminas precipitadas e acréscimos na descarga líquida acarreta em aumento na descarga de sedimentos (Steegen et al. 2000).

Em função do grau de relacionamento, conforme demonstrado na Figura 4, testou-se diversos modelos de regressão para obtenção da equação de ajuste entre os mesmos. Na Tabela 3 estão apresentados os modelos que 
tiveram melhor desempenho, grau de ajustamento, em função do coeficiente de determinação $\left(\mathrm{R}^{2}\right)$ e raiz quadrada do erro médio (RMSE).

Tabela 3. Resultado do ajustamento de modelos estatísticos para Descarga Sólida e Descarga Líquida

\begin{tabular}{ccc}
\hline Modelos & $\mathbf{R}^{\mathbf{2 *}}$ & RMSE** $^{*}$ \\
\hline Linear & 0,910 & 4,862 \\
Exponencial & 0,874 & 5,795 \\
Logarítmica & 0,867 & 5,928 \\
Potencial & 0,911 & 4,824 \\
\hline
\end{tabular}

*R ${ }^{2}$ - Coeficiente de determinação; **RMSE- Raiz Quadrada do Erro Médio.

O modelo que melhor explicou o comportamento da descarga de sedimentos em função da descarga líquida foi o potencial (Tabela 3). O modelo ajustado está apresentado na Figura 5.

Figura 5. Descarga de Sedimentos $\left(\right.$ Ton.dia $\left.^{-1}\right)$ e Descarga Líquida $\left(\mathrm{m}^{3} \cdot \mathrm{s}^{-1}\right)$.

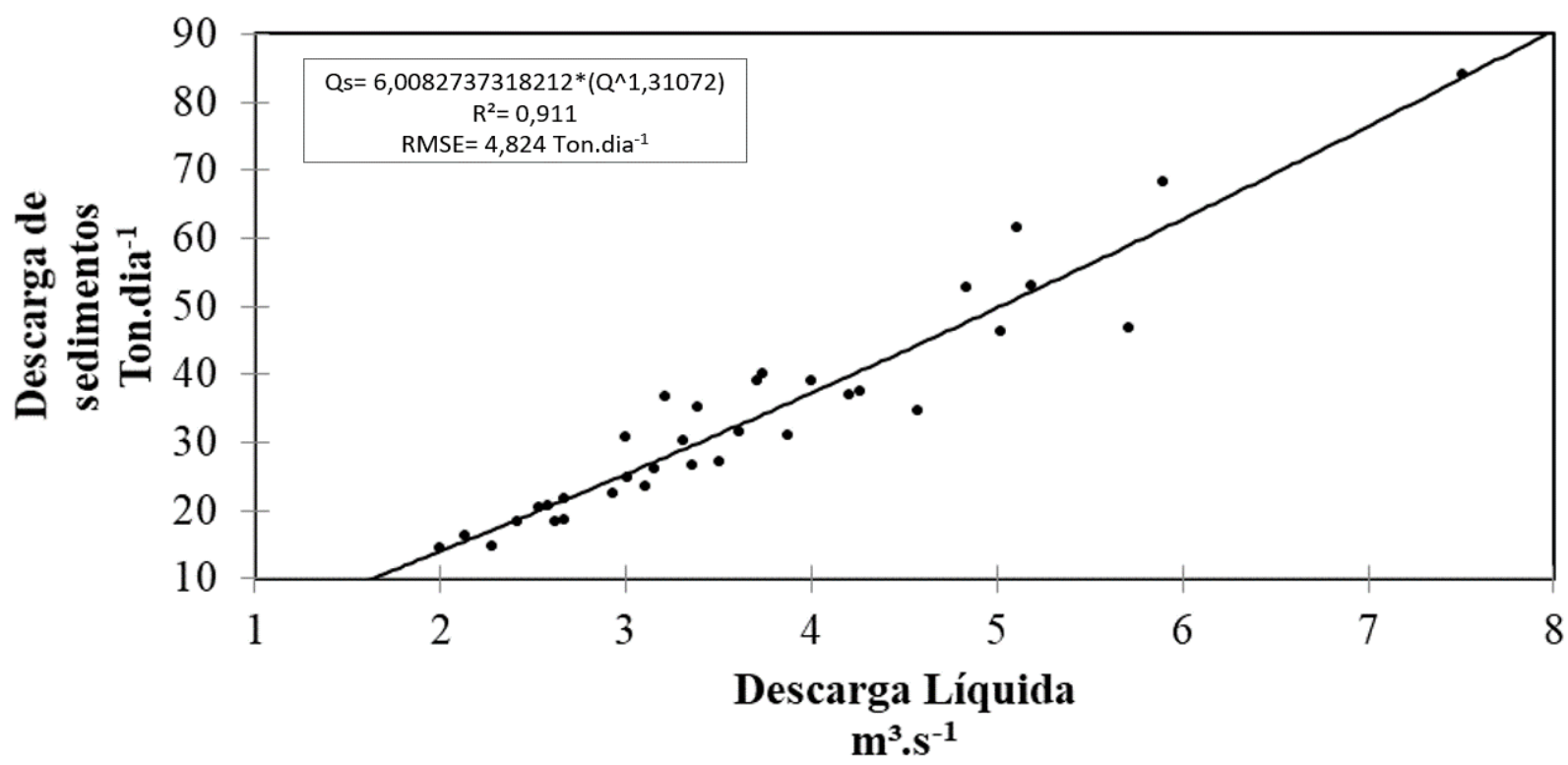

Para o modelo potencial o $\mathrm{R}^{2}$ apresentou valor de 0,911 demonstrando que a descarga de líquida é capaz de explicar cerca de $90 \%$ da descarga de sedimentos na BHCG para a faixa de vazão obtida nesta pesquisa. O valor de RMSE é comumente utilizado para aferir a qualidade do ajuste de um modelo, sendo a diferença entre o valor predito e o observado igual a zero considerado como ideal. O valor obtido de 4,824 Ton.dia ${ }^{-1}$ para a RMSE indica uma superestimação da descarga sólida por esse modelo.

A descarga líquida é uma variável mais fácil de ser monitorada com a utilização das curvas chave sendo disponibilizadas pela Agência Nacional das Águas (ANA). O mesmo não é válido para o monitoramento de sedimentos em bacias hidrográficas, sendo mais agravado em bacias menores, como é o caso da BHCG. Tal aspecto torna a utilização do modelo obtido associado com as medições da descarga líquida uma ferramenta útil no manejo e gestão dos recursos hídricos na BHCG

A partir do modelo obtido é possível estimar com maior precisão descargas de sedimentos em condições de menores valores de descarga líquida (Figura 5). Deste modo é necessário mais coletas em descargas líquidas mais elevadas proporcionando maior quantidade de pares ordenados visando a melhoria no ajuste do modelo.

A partir da comparação entre a precipitação acumulada nos 7 dias antecedentes obtidos a partir do INMET E CEMADEN (2016) e a descarga de sedimentos (Figura 6) percebe-se que quanto maior lâmina precipitada nos 
dias que antecederam as coletas, maior a produção de sedimentos. Em estudo realizado em Alegre no Espírito Santo, Uliana et al. (2015) demonstraram a tendência do aumento entre vazão e precipitação, com acréscimos proporcionais entre eles, sendo o aumento na vazão reflexo da precipitação acumulada do período anterior que, por sua vez, reflete em alterações nos parâmetros de qualidade de água, englobando a descarga de sedimentos. Características semelhantes foram encontradas em outros trabalhos da área hidrossedimentológica como Macêdo et al. (2013) e Schmidt e Mattos (2013).

Figura 6. Precipitação acumulada em sete dias antecedentes à amostragem e sua influência na descarga sedimentológica.

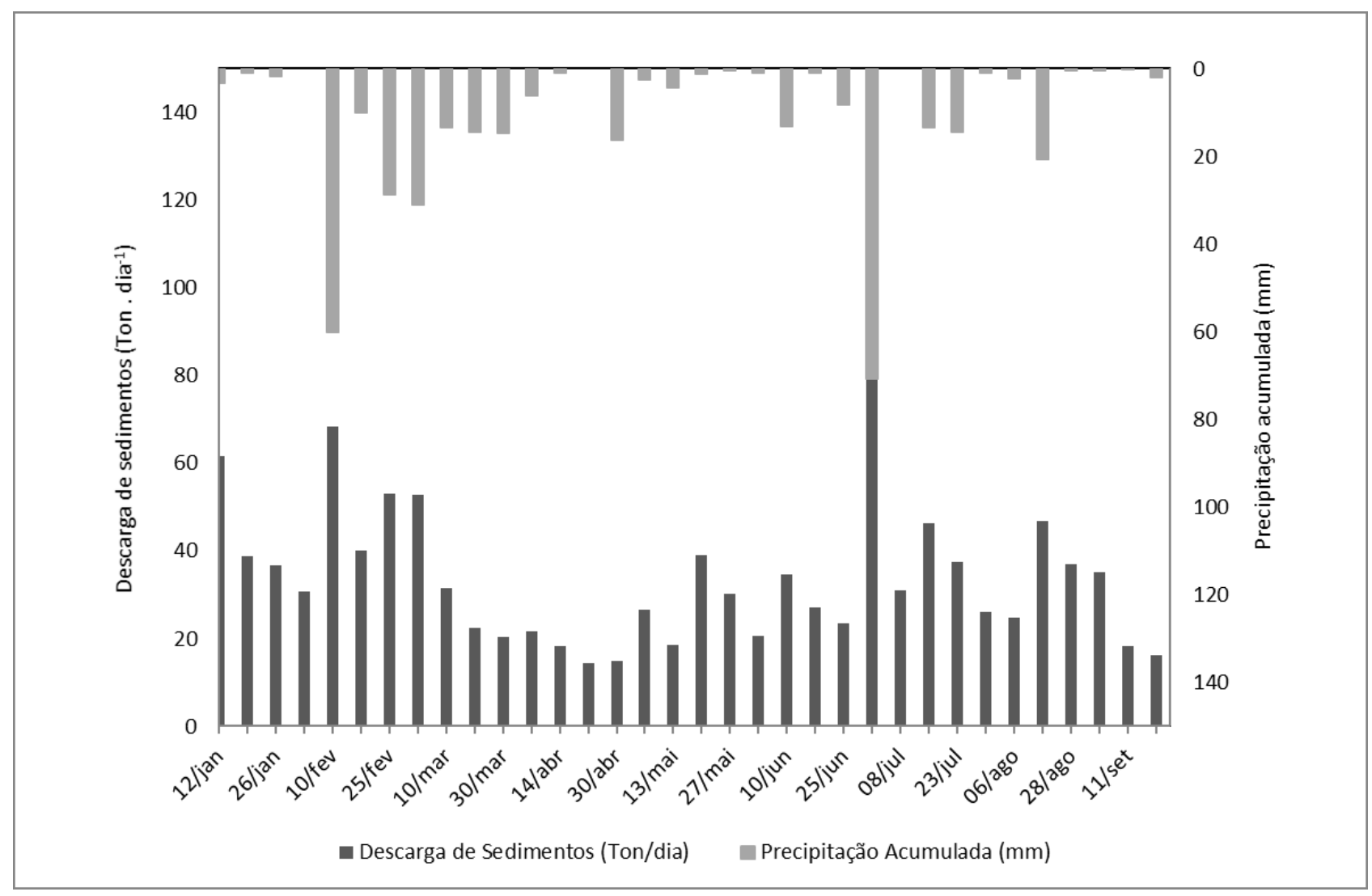

Conforme demonstrado por Vestena (2009) em seu estudo na bacia hidrográfica de Caeté em Alfredo Wagner/SC, a vazão é fortemente influenciada pela ação pluviométrica, sendo que o estudo da ação contributiva da precipitação nos níveis de vazão auxilia no entendimento dos processos que atuam no transporte de sedimentos, bem como sua deposição nos cursos d'água. Oliveira, Santos e Nishiyama (2016) apontam para a forte relação entre vazão e precipitação sendo que grandes anomalias de precipitação quase sempre resultam em anomalias de descarga nos rios. Vilanova (2014) percebeu no alto do rio Mogi-Guaçu os impactos dos baixos níveis de precipitação, que resultaram em menores valores encontrados para a vazão.

Bacias predominantemente ocupadas por pastagem, principalmente às degradadas como ocorre na BHCG (Figura 2), favorece a formação do escoamento superficial e o impacto das gotas da chuva diretamente na superfície do solo e consequentemente o aumento no desprendimento das partículas de solo acarretando o aumento da descarga de sedimentos (Kemerich et al. 2014). Tal aspecto afeta à comunidade, uma vez que produz prejuízos que interferem no equilíbrio do meio ambiente, prejudicando a fauna e flora do ecossistêmica e aspectos econômicos e sociais (Peixoto 2019).

No que tange os problemas provocados pela descarga de sedimentos cita-se a degradação do uso consumptivo da água, aumentando o custo de tratamento; impacto a vida aquática e degradação da água especificamente para o abastecimento, recreação e consumo industrial; impedimento a penetração da luz e do calor, reduzindo a atividade 
da fotossíntese necessária à salubridade dos corpos hídricos; atuação como portador de bactérias, vírus e de poluentes, como por exemplo nutrientes químicos, inseticidas, herbicidas e metais pesados; perturbação na forma do canal transportador; e pode vir a prejudicar a navegação ou elevar o nível d'água, elevando a frequência de enchentes (Carvalho 2008).

A ocupação do solo em grande parte por pastagens contribui para modificações do sistema natural de bacia hidrográfica, de modo a influenciar no fluxo da vazão através da bacia hidrográfica pelos processos de acúmulo de sedimentos ao curso d'água (Didoné 2013), proporcionando retardamento ou desvio da precipitação à bacia hidrográfica, resultando ainda em possíveis riscos relacionados à transbordamentos e enchentes aos limites do curso d'água.

Estudos de Silva et al. (2005) e Sperandio et al. (2012) analisando diferentes coberturas vegetais pela ação da erosão hídrica evidenciam maiores resultados de perda de solo em solo com cobertura de pastagens, o que se confirma pela interferência antrópica e animal na área, principalmente pelo pisoteio de animais, com o desenvolvimento de "trilhas bovinas" que modificam o micro relevo da área, bem como a compactação do solo, em concomitância as atividades de manejo de pastagens, com roçagem e remoção de plantas invasoras.

Deste modo um bom planejamento na instalação da pastagem bem como sua condução (manejo) tende a reduzir essas perdas de solo, com o aumento da cobertura vegetal, que busca minimizar o impacto direto de gotas de chuva com barreiras ao escoamento superficial, levando-a aos limites toleráveis. Portanto as áreas destinadas à pastagem devem ser preservadas de modo que não intensifique os níveis de perda de solo evidenciados pela erosão hídrica.

A erosão é causada pela perda do solo sendo influenciada conforme a variabilidade do mesmo, em que as taxas de perdas dependem da susceptibilidade à erosão (Alvarenga e Souza 1995). Sabe-se ainda que a erosão hídrica é um dos principais fatores responsáveis pelo decréscimo na produtividade do solo, uma vez que provoca perdas de solo, água e nutrientes (Schaefer et al. 2002). Sendo constatado que regiões onde a perda do solo ocorre com maior intensidade e magnitude, ocorre a redução da produtividade agrícola (Galharte et al. 2014). As perdas hídricas e químicas pela enxurrada em áreas agrícolas de pastagem podem ainda acarretar problemas de eutrofização dos cursos d'água (Lal 1998), evidenciando seus riscos.

Os solos podem possuir maior ou menor suscetibilidade à erosão, mesmo para condições semelhantes de cobertura vegetal, declividade e práticas de manejo, segundo fatores intrínsecos e extrínsecos, sendo tais diferenças devidas às propriedades do próprio solo denominadas erodibilidade do solo (Bertoni; Lombardi Neto 1985). A erodibilidade do solo representa, portanto, o efeito de maneira integrada dos processos reguladores a infiltração de água e resistência à desagregação e transporte de partículas do solo, referindo assim a predisposição à erosão (do Vale Junior et al. 2010).

Menores valores de erodibilidade indicam solos menos suscetíveis a erosão, desprendimento e perda de solo. Dentre as principais classes de solos identificadas com baixa e muito baixa susceptibilidade à erosão para a bacia hidrográfica do rio Catolé Grande destacam-se os Latossolos, Nitossolo, Chernossolo e Argissolo respectivamente. No estudo de Silvia e Alvares (2007) concluíram-se que os valores de erodibilidade médias (K) oscilaram entre 0,0097 para os Planossolos e 0,0610 para os Organossolos, sendo as classes de solo encontradas para a bacia de estudo do rio Catolé Grande com valores medianos de $\mathrm{K}$ e, portanto, com suscetibilidade à erosão medianas, porém significantes.

Conforme definição de Carvalho (1994) para estudos hidrossedimentológicos os intervalos de perda de solo utilizados seguem descritos na Tabela 4 . Neste estudo a descarga de sedimentos máxima encontrada para a coleta de $02 /$ jul de 84,13 Ton.dia ${ }^{-1}$, determinou uma perda de solo de 0,106 Ton.(ha.ano- ${ }^{-1}$ e desta forma classificado como perda de solo baixa, com limites de 0 a 15 Ton.(ha.ano) ${ }^{-1}$. 
Tabela 4. Intervalos de perda de solo e sua respectiva classificação

\begin{tabular}{cc}
\hline $\begin{array}{c}\text { Intervalos de perda de solo } \\
\text { Ton.(ha.ano) }\end{array}$ & Classificação \\
\hline $0-15$ & Baixa \\
$15-50$ & Moderada \\
$50-120$ & Forte \\
$120-200$ & Muito Forte \\
\hline
\end{tabular}

Fonte: Carvalho (1994)

Ao apresentar um solo com risco à erosão mediana, na maior parte da área da bacia, com atividade de uso da cobertura do solo invasiva, os níveis de perda de solo, representado pela descarga de sedimentos, são considerados de baixa magnitude para a bacia hidrográfica de estudo.

A eficiente análise e entendimento da perda de solo conjuntamente com a descarga líquida de cursos d'água são essenciais para um bom planejamento e gerenciamento de bacias hidrográficas. As descargas líquidas e sólidas afetam aspectos ambientais, econômicos e sociais inerentes à população que faz uso e depende, direta ou indiretamente, dos recursos naturais provenientes da bacia hidrográfica. Deste modo os sedimentos e os problemas deles advindos representam um grande desafio para a gestão dos recursos hídricos, sendo necessário a evidência de estudos com tal caráter de abordagem.

A concentração de sedimentos em um curso d'água pode influenciar em diferentes variáveis de qualidade de água, conforme demonstrado em trabalhos de Barreto et al. (2014) e Souza e Gastaldini (2014). Com base no levantamento da concentração de sedimentos pela presença de sólidos em suspensão, a mesma se relaciona fortemente com a variável de turbidez na qual refere-se à medida da interferência da passagem de luz através do meio líquido (Matos 2012), deste modo, normalmente tais variáveis possuem relação significativa entre si.

No rio Catolé Grande durante o período de amostragem para o ano de 2015 os valores de turbidez encontrados mantiveram-se próximos ao longo do período de análise como demonstrado na Figura 7. Contudo, nota-se picos de turbidez para as coletas $10 / \mathrm{fev}$ e $02 /$ jul, às quais coincidirem com o período de grande lâmina precipitada e com o pico de descarga de sedimentos, justificando a ação da precipitação e influência da mesma no escoamento superficial, que ao carrear partículas sólidas interfere na turbidez do corpo hídrico.

Figura 7. Valores de turbidez na seção de controle no rio Catolé Grande no período analisado.

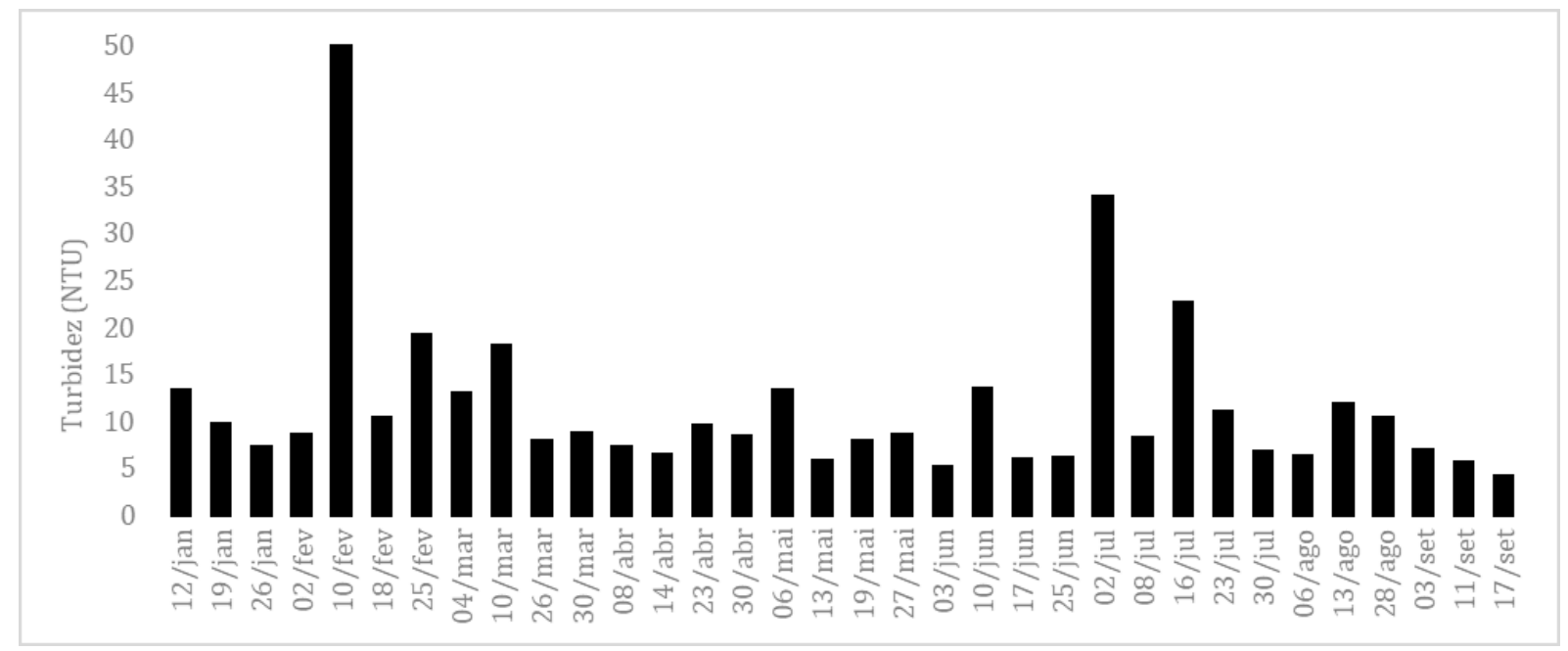

A Resolução CONAMA 357 (BRASIL 2005) estabelece limites de valores para Classe 2 de corpos de água doce para turbidez de até 100 UNT, desta forma pode-se dizer que mesmo com as variações percebidas ao longo do ano para o rio Catolé Grande, os valores encontram-se abaixo do limite disposto em tal resolução, apresentando portanto condição de qualidade para tal variável de estudo. 
O efeito da precipitação no desprendimento e transporte de sólidos e seu forte impacto no aumento da turbidez dos cursos d'água foi também percebido por Sari et al. (2017), que demonstraram uma forte interferência entre tais variáveis ainda considerando em seu estudo e efeito da granulometria de sólidos em suspensão.

A atividade agropecuária, de caráter ativo na região na BHCG, possibilita uma maior exposição do solo a processos erosivos. A erosão do solo pode ser afetada pelo pisoteamento do solo por animais, o que reduz a taxa de infiltração da água e favorece o escoamento superficial, que por sua vez é o responsável pelo carreamento dessas partículas sólidas até os cursos d'água acarretando no aumento dos valores de turbidez.

$\mathrm{Na}$ Figura 8 está representado o comportamento da descarga de sedimentos em função da turbidez, sendo verificado que não existe uma relação direta entre os dados analisados no período de estudo. As relações estatísticas que medem o grau de associação entre duas variáveis não foram satisfatórias entre tais variáveis, sendo a inclinação da linha de tendência ajustada à nuvem de pontos não representativa, não sendo possível a obtenção da equação que explica a variação da variável dependente pela variação da variável independente. Em estudo, Navratil et al. (2011) encontraram o melhor ajuste da curva com a equação potencial e Pinheiro et al. (2013) para equação polinomial de terceiro grau, o que não foi possível determinar neste estudo.

Figura 8. Curva comportamento Descarga de Sedimentos e Turbidez.

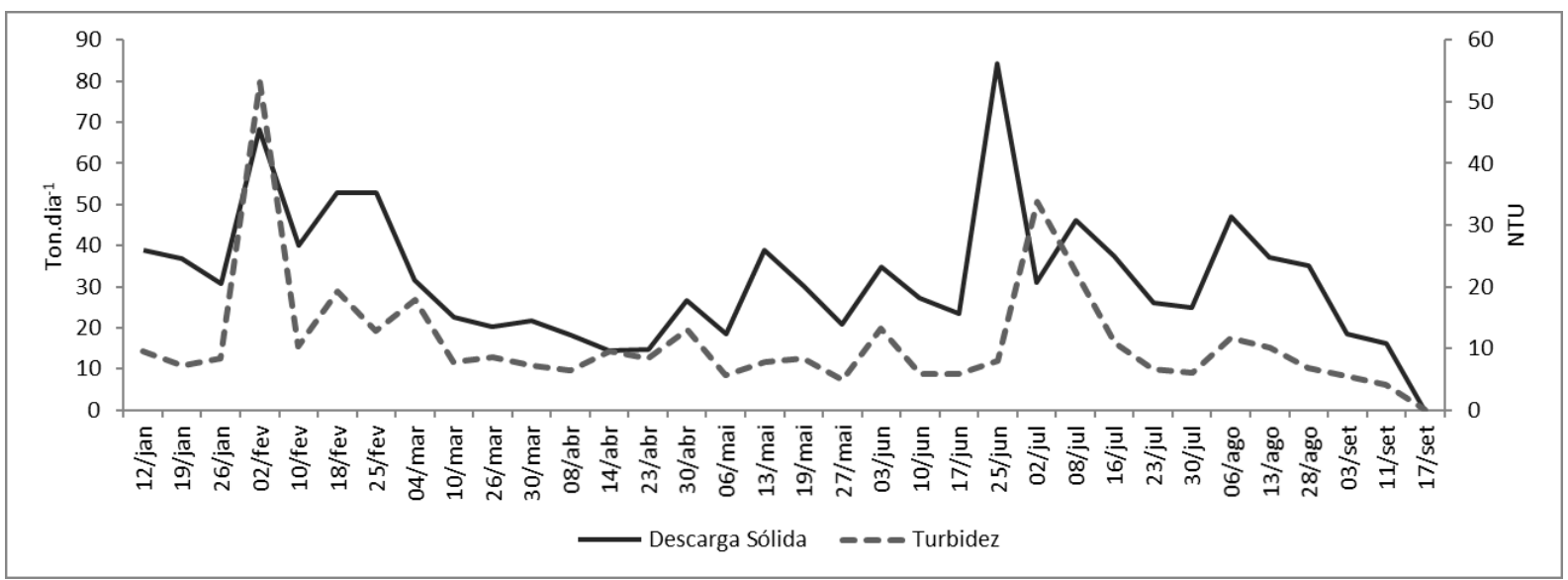

Deste modo são necessários estudos e análises complementares com o objetivo de melhoria da compreensão das tecnologias que utilizam a turbidez para estimativa da concentração de sedimentos e posterior descarga sólida pela aplicação de dados de descarga líquida, bem como os fatores que interferem nessas medições, levando em conta características dos rios e das bacias hidrográficas brasileiras (Sari, Castro, Kobiyama 2015).

É importante considerar que o efeito da turbidez da água está normalmente associado à quantidade de material de sólido em suspensão, porém não depende estritamente desta relação, mas também de fatores relacionados à composição do material, tanto mineral como orgânica (Santos et al. 2013), não dependendo apenas da concentração de sedimentos, mas, ainda das propriedades das partículas de sedimentos transportadas, das características químicas e biológicas do escoamento e do sensor de turbidez utilizado (Sari et al. 2017). Desta maneira as partículas carreadas podem não influenciar nos níveis de turbidez verificados no rio, sendo necessária a diferenciação e identificação da natureza da concentração dos sólidos ali presentes, em que somente os sólidos suspensos, refletem em alterações na turbidez analisada.

Evidência, portanto, neste estudo a importância da gestão integrada do uso da terra e seus impactos aos recursos hídricos. No caso dos recursos hídricos adota-se a bacia hidrográfica como unidade de planejamento e gerenciamento, enfatizando deste modo a integração econômica e social para a tomada de decisão (Cazula e Mirandola 2010). Contudo, faz-se necessária uma integração interdisciplinar do estudo dos impactos das ações antrópicas visando conservação e preservação do uso do solo e dos recursos hídricos, sob gestão integrativa e participativa, de forma que sejam minimizados impactos negativos e se garanta o desenvolvimento sustentável 
(Souza e Fernandes 2000) que beneficie os diferentes usuários de água e sua relação com o meio ambiente (Chaves et al. 2004).

\section{ConClusões}

- A perda de solo na BHCG máxima encontrada nas coletas foi classificada como baixa com magnitude de 0,106 Ton.(ha.ano) ${ }^{-1}$;

- O modelo potencial foi o que melhor representou a relação entre a descarga de sedimentos (Qs) em função da descarga líquida (Q) durante o período observado;

- Percebeu-se que a precipitação nos dias que antecederam as coletas influencia diretamente na descarga de sedimentos da BHCG;

- Não foi verificada relação direta entre o comportamento da descarga de sedimentos em função da turbidez, entre os dados analisados no período de estudo na BHCG.

- O conhecimento do comportamento hidrológico no que tange o estudo da concentração e descarga de sedimentos em corpos hídricos é de fundamental importância, uma vez que serve de auxílio para definição de estratégias para controle e mitigação de impactos ambientais evidenciados pela ação antrópica na modificação do uso e ocupação do solo, sendo necessária a continuidade de estudos com tal direcionamento.

\section{Agradecimentos}

À Fundação de Amparo à Pesquisa do Estado da Bahia - FAPESB e ao Conselho Nacional de Pesquisa e Desenvolvimento $(\mathrm{CNPq})$ pelo apoio financeiro concedido para realização desta pesquisa. À Universidade Estadual do Sudoeste da Bahia pela estrutura e bolsas concedidas.

\section{REFERÊNCIAS}

Alvarenga MIN, Souza JA. (1995). Atributos do solo e impacto ambiental, UFLA: FAEPE, n 205. Brasil: Lavras. 1997p.

Amorim J da S. Produção de água na Bacia Hidrográfica do Rio Catolé Grande utilizando o modelo hidrológico SWAT. / Jhones da Silva Amorim. - Itapetinga-BA: Universidade Estadual do Sudoeste da Bahia, 2016.

APHA- Standard Methods For The Examination Of Water And Wastewater. (2012). 22nd Ed.: American Public Health Association, American Water Works Association, WaterEnvironment Federation. Washington.

Barreto LV, de Souza Fraga, M, Barros FM, Rocha FA, da Silva Amorim J, de Carvalho, SR., ... e da Silva, DP. (2014). Relação entre vazão e qualidade da água em uma seção de rio/Relation ship between stream flow and water quality in a river section. Revista Ambiente \& Água, 9(1), 118. DOI: <http://dx.doi.org/10.4136/ambi-agua.1278>.

Basso LA, Moreira LGR, \&Pizzato F. (2011). A influência da precipitação na concentração e carga de sólidos em cursos d'água urbanos: o caso do arroio Dilúvio, Porto Alegre-RS. Geosul, 26(52), 145-163.

Bertoni J, Lombardi Neto F. (1999). Conservação do solo. 4. ed. São Paulo: Ícone. 355p. 
BRASIL (Governo do), CONAMA. Resolução Nº 357, DE 17 DE MARÇO DE 2005. Dispõe sobre a classificação dos corpos de água e diretrizes ambientais para o seu enquadramento, bem como estabelece as condições e padrões de lançamento de efluentes, e dá outras providências. 27 p.

Carvalho $\mathrm{N}$ de O. Hidrossedimentologia prática: Interciência. (2008). $2^{a}$ Ed., rev., atual. e ampliada. Rio de Janeiro.

Carvalho N de O. Hidrossedimentometria prática. (1994) Rio de Janeiro: CPRM - Eletrobras. 372 p.

Carvalho NO, Júnior NPF, dos Santos PMC. \& Lima JEFW. Guia De Práticas Sedimentológicas. (2000). Agência Nacional de Energia Elétrica. Brasília.

Cazula LP \& Mirandola PH. (2010). Bacia hidrográfica - conceitos e importância como unidade de planejamento: um exemplo aplicado na bacia hidrográfica do Ribeirão Lajeado/SP-Brasil. Revista Eletrônica da Associação dos Geógrafos Brasileiros, n.12, 101-124 pp.

CEMADEN (Centro Nacional de Monitoramento e Alertas de Desastres Naturais). Disponível em:<http://www. cemaden.gov.br/>. Acesso em 07 de Fevereiro de 2016.

CETESB (Companhia de Tecnologia de Saneamento Ambiental do estado de São Paulo). Guia nacional de coleta e preservação de amostras: água, sedimento, comunidades aquáticas e efluentes líquidos. (2011) Companhia Ambiental do Estado de São Paulo; Organizadores: Carlos Jesus Brandão [et al.]. São Paulo: CETESB; Brasília.

Chaves, HML, Braga B, Domingues AF, e Santos DG. (2004). Quantificação dos benefícios ambientais e compensações financeiras do Programa do Produtor de Água/ANA: II. Aplicação. R. Bras. Rec. Hídricos, 9:15-21.

Da Rocha Junior PR, Andrade F V, de Sá Mendonça E, Donagemma G K, Fernandes RBA, Bhattharai R, \&Kalita PK. (2017). Soil, water, and nutrientlossesfrom management alternatives for degradedpasture in BrazilianAtlanticRainforestbiome. Science of the Total Environment, 583, 53-63.

Da Rocha Junior PR, Donagemma GK, Andrade FV, Passos RR, Balieiro FDC, Mendonça EDS, \& Ruiz HA. (2014). Cansoilorganiccarbon pools indicatethedegradationlevels of pastures in theAtlantic Forest biome. Embrapa Solos-Artigo em periódico indexado (ALICE).

Didoné, E. J. (2013). Erosão bruta e produção de sedimentos em bacia hidrográfica sob plantio direto no planalto do Rio Grande do Sul.

Do Vale Júnior JF, da Silva Barros L, de Sousa MIL, \& Uchôa SCP. (2010). Erodibilidade e suscetibilidade à erosão dos solos de cerrado com plantio de Acaciamangium em Roraima. Revista Agro@mbiente On-line, 3(1), 1-8.

EMBRAPA (Empresa Brasileira De Pesquisa Agropecuária). Centro Nacional de Pesquisa de Solos. Sistema brasileiro de classificação de solos. 2.ed. Rio de Janeiro, 2006. 306p.

ESRI A. ArcGIS 10.1. (2012). Environmental Systems Research Institute, Redlands, CA, USA.

FAPEAL- Fundação de Amparo à Pesquisa do Estado de Alagoas. (2019). Expedição desbrava o Rio São Francisco e apresenta relatório. Disponível em: < http://fapeal.br/destaque/2019/09/11/expedicao-desbrava-o-rio-sao-francisco-eapresenta-relatorio/>. Acesso em 26 de Setembro de 2019. 
Galharte CA, Villela JM, Crestana S. (2014). Estimativa da produção de sedimentos em função da mudança de uso e cobertura do solo. Revista Brasileira de Engenharia Agrícola e Ambiental, v. 18, n. 2, p. 188-193.

Haimann M, Liedermann M, Petra LALK, \&Habersack H. (2014). Anintegratedsuspendedsedimenttransportmonitoring and analysisconcept. InternationalJournal of SedimentResearch, 29(2), 135-148.

Harrington ST, \& Harrington JR. (2013). An assessment of thesuspendedsediment rating curve approach for loadestimationonthe Rivers Bandon and Owenabue, Ireland. Geomorphology, 185, 27-38.

INMET (Instituto Nacional de Meteorologia). Disponível em:<http://www.inmet.gov.br/portal/>. Acesso em 07 de Fevereiro de 2016.

Jemai I, Aissa NB, Guirat SB, Ben-Hammouda M, \&Gallali, T. (2013). Impact of three and sevenyears of notillageonthesoilwaterstorage, in theplant root zone, under a drysubhumidTunisianclimate. Soil and tillageresearch, 126, 26-33.

Keesstra S, Pereira P, Novara A, Brevik EC, Azorin-Molina C, Parras-Alcántara L, ... \&Cerdà, A. (2016). Effects of soil management techniquesonsoilwatererosion in apricotorchards. Science of the Total Environment, 551, 357-366.

Kemerich PD, Martins SR, Kobiyama M, Flores CEB, de Borba WF, FernandesGDÁ, ... \&CherubinMR. (2014). Infiltração e escoamento superficial sob diferentes usos e ocupação em uma bacia hidrográfica. Anuário do Instituto de Geociências, 37(2), 75-88.

Lal R. (1984). Soil erosion from tropical arable lands and its control. In Advances in Agronomy Academic Press. Vol. 37, pp. 183-248.

LAPIG (Laboratório de Processamento de Imagens e Geoprocessamento. Instituto de Estudos Socioambientais (IESA) da Universidade Federal de Goiás (UFG)). Disponível em <http://maps.lapig.iesa.ufg.br/lapig.html $>$. Acesso em Dezembro de 2018.

Lima EM, \& Pinto JESDS. (2011). Bacia do rio catolé, Bahia-Brasil: bases geoambientais e socioeconômicas para a gestão da água e do solo. Revista Geográfica de América Central, 2, 1-16.

Luíz AME, Pinto MLC, \& de Oliveira Sheffer EW. (2012). Parâmetros de cor e turbidez como indicadores de impactos resultantes do uso do solo, na bacia hidrográfica do rio Taquaral, São Mateus do Sul-PR. Raega- O Espaço Geográfico em Análise, 24.

Macêdo MDNC, Dias HCT, Coelho FMG, Araújo EA, de Souza MLH, \& Silva E. (2013). Precipitação pluviométrica e vazão da bacia hidrográfica do Riozinho do Rôla, Amazônia Ocidental/Rainfall and flow of the Riozinho do RôlaBasinon Western Amazon. Revista Ambiente \& Água, 8(1), 206. DOI: <http://dx.doi.org/10.4136/ambi-agua.809>.

Matos, A.T. Qualidade do meio físico ambiental: práticas de laboratório. (2012). Viçosa, MG. Ed. UFV. 150p.

Merten GH, \&Minella JP. (2013). The expansion of Brazilianagriculture: soilerosionscenarios. InternationalSoil and WaterConservationResearch, 1(3), 37-48.

Morais RCS. (2015). Estimativa De Produção E Trasporte De Sedimentos Na Bacia Hidrográfica Do Rio Parnaíba, Nordeste Do Brasil. REVISTA EQUADOR, 4(4), 81-97. 
Navratil O, Esteves M, Legout C, Gratiot N, Nemery J, Willmore S, \&Grangeon T. (2011). Global uncertaintyanalysis of suspendedsedimentmonitoringusingturbidimeter in a smallmountainousrivercatchment. Journal of Hydrology, 398(3-4), 246-259.

Nogueira PF, Cabral JBP, \& Oliveira SF. (2012). Análise da concentração dos sólidos em suspensão, turbidez e tds nos principais afluentes do reservatório da UHE Barra dos Coqueiros-GO. Goiás: Revista Geonorte, 3(4), 485-494.

Oliveira Santos V, \&Nishiyama L. (2016). Tendências Hidrológicas No Alto Curso Da Bacia Hidrográfica Do Rio Uberaba, Em Minas Gerais. Caminhos de Geografia, 17(58), 205-221.

Peixoto R de A O. (2019). Estudo do transporte de sedimentos na bacia hidrográfica do Rio Jordão - UPGRH-PN 1 [recurso eletrônico]. Dissertação de Mestrado. 146 pg.

Pinheiro EAR, Araújo JD, Fontenele SDB, \& Lopes JWB. (2013). Calibração de turbidímetro e análise de confiabilidade das estimativas de sedimento suspenso em bacia semiárida. Water Res. Irrig. Manag, 2(2), 103-110.

Pruski FF, Silva DD da, Koetz M. Estudo de vazão em cursos d’água. (2006). Viçosa: AEAGRI (Série Caderno Didático no 43), p. 151.

Santos QR, de Souza Fraga M, Uliana EM, dos Santos Reis A, \& Barros FM. (2013). Monitoramento da qualidade da água em uma seção transversal do rio Catolé, Itapetinga-BA.Enciclopédia Biosfera, Centro Científico Conhecer - Goiânia, 9(16), 1503-1519p.

Sari V, Castro, NDR, \& Kobiyama M. (2015). Estimativa da concentração de sedimentos suspensos com sensores ópticos: revisão. Revista Brasileira de Recursos Hídricos, 20(4), 816-836.

Sari V, Pereira MAF, Castro NMDR, \& Kobiyama M. (2017). Efeitos do tamanho da partícula e da concentração de sedimentos suspensos sobre a turbidez. Engenharia sanitária e ambiental: órgão oficial de informação técnica da ABES.22 (2), p. 213 219.

Schaefer CER, Silva DD, Paiva KWN, Pruski FF, Albuquerque Filho MR, \& Albuquerque MA. (2002). Perdas de solo, nutrientes, matéria orgânica e efeitos microestruturais em Argissolo Vermelho-Amarelo sob chuva simulada. Pesquisa Agropecuária Brasileira, 37(5), 669-678.

Schmidt DM, \& Mattos A. (2013). Dinâmica dos regimes de precipitação e vazão da bacia hidrográfica do alto Piranhas-AçuPB. Sociedade e Território, 25(2), 67-77.

Shakesby RA, Bento CP, Ferreira CS, Ferreira AJ, Stoof CR, Urbanek E, \&Walsh RP. (2015). Impacts of prescribedfireonsoilloss and soilquality: an assessment basedonanexperimentally-burnedcatchment in central Portugal. Catena, 128, 278-293.

Shi ZH, Fang NF, Wu FZ, Wang L, Yue BJ, \& Wu GL. (2012). Soilerosion processes and sedimentsortingassociatedwithtransportmechanismsonsteepslopes. Journal of Hydrology, 454, 123-130.

Silva AM, \& Alvares CA. (2007). Levantamento de informações e estruturação de um banco dados sobre a erodibilidade de classes de solos no estado de São Paulo. Geociências (São Paulo), 24(1), 33-41.

Silva AM, Silva MLN, Curi N, de Lima JM, Avanzi JC, \& Ferreira MM. (2005). Perdas de solo, água, nutrientes e carbono orgânico em Cambissolo e Latossolo sob chuva natural. Pesquisa Agropecuária Brasileira, 40(12), 1223-1230. 
Silva Jr VP, Montenegro AA, Silva TP, Guerra SM, \& Santos ES. (2011). Produção de água e sedimentos em bacia representativa do semiárido pernambucano. Revista Brasileira de Engenharia Agrícola e Ambiental, 15(10), 1073-1082.

Sousa GB, Martins Filho MV, \& Matias SS. (2012). Perdas de solo, matéria orgânica e nutrientes por erosão hídrica em uma vertente coberta com diferentes quantidades de palha de cana-de-açúcar em Guariba-SP. Engenharia Agrícola, 490-500. DOI: $10.1590 /$ S0100-69162012000300008.

Souza MM, \& Gastaldini MDCC. (2014). Avaliação da qualidade da água em bacias hidrográficas com diferentes impactos antrópicos. Engenharia Sanitária e Ambiental, 19(3), 263-274. DOI: 10.1590/S1413-41522014019000001097.

Souza ER, \& Fernandes MR. (2000) Sub-bacias hidrográficas: unidades básicas para o planejamento e a gestão sustentáveis das atividades rurais. Inf. Agropec., Belo Horizonte, 207: 15-20.

Sperandio HV, Cecílio RA, Campanaro W, CARO C, \& HOLLANDA M. (2012). Avaliação da erosão hídrica pela alteração na superfície do solo em diferentes coberturas vegetais de uma sub-bacia hidrográfica no Município de Alegre, ES. Semina: Ciências Agrárias, 1411-1418.

Steegen A. et al. Sedimentexportbywaterfromanagriculturalcatchment in theLoamBelt of central Belgium. (2000). Geomorphology. 33, p. 2536.

Uliana EM, Da Silva DD, Morgan Uliana E, Silveira Rodrigues B, \& de Paula Corrêdo L. (2015). Análise de tendência em séries históricas de vazão e precipitação: uso de teste estatístico não paramétrico. Ambiente \&Água-AnInterdisciplinaryJournal of Applied Science, 10(1).

Vestena LR. (2009). Análise da dinâmica hidrossedimentológica em uma bacia hidrográfica no sul do Brasil. Revista Sociedade \& Natureza, 21(3). DOI: 10.1590/S1982-45132009000300014.

Vilanova MRN. (2014). Tendências hidrológicas na região do alto rio Mogi-Guaçu, sul de Minas Gerais. Revista Agrogeoambiental, 6(3).DOI: 10.18406/2316-1817v6n32014601.

Zhao G, Mu X, Wen Z, Wang F, \& Gao P. (2013). Soilerosion, conservation, and eco-environmentchanges in theLoessPlateau of China. Land Degradation \& Development, 24(5), 499-510. 